\title{
Scope for design suggestions of hand tool used in performing agricultural activities
}

\author{
Sonia Langthasa, N. Bhattacharyya, M. Kalita and M. Baruah
}

Received: 09.08.2019; Revised: 25.10.2019; Accepted: 09.11.2019

See end of the paper for authors' affiliations Sonia Langthasa

Department of Family Resource Management and Consumer Science, College of Community Science, Assam Agricultural University, Jorhat (Assam) India Email : sonialangthasa867@ gmail.com
ABSTRACT : Work related musculoskeletal disorders mostly are major indicating parameter of occupational stress amongst the workers engaged in agricultural field and they are exposed to a combination of risk factors. Controlling of these problems or risks is accomplished by matching workers characteristics/work and workplaces/work tools details in a manner that improves worker's efficiency and productivity while decreasing the worker's risk of injury and discomfort. Keeping this in view a study was carried out to explore the scope for design suggestions for mostly used hand tool in performing selected agricultural activities. Survey was conducted to gather information from the selected households by following Probability Proportionate to Size (PPS) technique from two districts i.e., Jorhat and Karbi Anglong. The study further revealed that Machete was used by the farmers and found that they faced difficulty while using this tool due to handle design. Attempt was made to explore the design modification in the existing handle of the machete. While modifying the handle three parameters i.e., length, diameter and weight of the handle were considered. Accordingly suggestions for design modifications were generated based on ergonomic principles and recommendation suggested by Konz et al. (1993). Based on the feedback from the field trials handle length of $15 \mathrm{~cm}$ with diameter $4 \mathrm{~cm}$ and weight $2.30 \mathrm{~kg}$ was found to be very comfortable.

KEY WORDS: Agricultural activities, Hand tool, Machete, Musculoskeletal disorders, Occupational stress

- HOW TO CITE THIS PAPER : Langthasa, Sonia, Bhattacharyya, N., Kalita, M. and Baruah, M. (2019). Scope for design suggestions of hand tool used in performing agricultural activities. Asian J. Home Sci., 14 (2) : 380-384, DOI: 10.15740/HAS/AJHS/14.2/380-384. Copyright@ 2019: Hind Agri-Horticultural Society. 